\title{
The intravitreal injection: Variations in regulations, cost and reimbursement in Europe
}

\author{
S. Michels', M. Becker ${ }^{1,4}$, J. Wachtlin², S. Binder ${ }^{3}$ \\ 1 Department of Ophthalmology, Triemli Hospital Zurich, Switzerland \\ 2 Department of Ophthalmology, Sankt Gertrauden Hospital, Berlin, Germany \\ ${ }^{3}$ Department of Ophthalmology, Rudolf Foundation Clinic, Vienna, Austria \\ ${ }^{4}$ Department of Ophthalmology, University of Heidelberg, Heidelberg, Germany
}

Received 23 December 2011; accepted 25 January 2012

Summary: Background: Large randomized controlled clinical trials have established excellent evidence for the most frequent exudative macular diseases (neovascular age-realted macular degeneration, macular edema due to diabetes and retinal vein occlusions) how to treat with intravitreal vascular endothelial growth factor inhibitors. Due to multiple limitations such optimal, best evidence-based treatment is hardly manageable in any European country.

Material and Methods: The subsequent overview outlines the key factors and their variability throughout Europe that limit the chance for adequate patient treatment. To outline the differences a survey was conducted among European retina specialists. Among the key limitations for optimal treatment are the drug label valid throughout the European Union (EU) for the most commonly used approved anti-VEGF drug ranibizumab. Below the EU-wide regulations are the national and partly regional restrictions for performing and reimbursing intravitreal injections. Further restrictions can be of relevance at the level of each institution performing intravitreal injections, including budget restrictions and limitations on the number of injections performed. The results of the survey indicate significant differences throughout Europe.

Results: Among the key differences is the time to the final national decision on reimbursement, which can take several years in some European countries. Further differences exist among many countries on who and which institutions can conduct intravitreal injections. In most countries this is dependent on the reimbursement through the health care system. Especially in eastern European countries, institutions being officially reimbursed for intravitreal injections - are submitted to further restrictions such as limited budgets or a limited number of injections per year. Additional relevant differences exist regarding the requirements for the injection room, ranging from just a designated room to a fully equipped operating room. This has in addition to safety significant im-

Correspondence: Stephan Michels, M.D., Department of Ophthalmology, Triemli Hospital Zurich, Birmensdorferstrasse 497, 8063 Zurich, Switzerland, E-Mail: stephan.michels@triemli.stzh.ch plications on cost and time-efficient patient treatment. The reimbursement for the intravitreal injection procedure at institutions with official reimbursement by the health care system varies throughout Europe from about 80 to $600 €$. Unfortunately, in many countries the organizational structures and incentives have - to the disadvantage of patients and treating ophthalmologists - not yet been adopted to the needs of the era of intravitreal injections.

Conclusions: With a growing number of affected and by intravitreal anti-VEGF injections treatable patients there will be an increasing pressure on improving access to adequate treatment. More uniformity regarding requirements and reimbursement throughout Europe is desirable. Unfortunately a further trend to regionalization is observed.

Key words: intravitreal injection, ranibizumab, bevacizumab, reimbursement

\section{Die intravitreale Injektion: Unterschiedliche Vorgaben, Kosten und Kostenerstattung in Europa}

Zusammenfassung: Hintergrund: Grosse prospektive, randomisierte, kontrollierte klinische Studien haben für den intravitrealen Einsatz von Inhibitoren des vaskulären endothelialen Wachstumsfaktors (VEGF) klare Behandlungsvorgaben mit höchstem Evidenzniveau gegeben. Dies gilt für die häufigsten exsudativen Makulaerkrankungen (neovaskuläre, altersbezogene Makuladegeneration, Makulaödem im Rahmen eines Diabetes oder eines venösen, retinalen Gefässverschlusses). Aufgrund zahlreicher Faktoren ist jedoch die Umsetzung einer optimalen, Evidenz basierten intravitrealen Therapie in kaum einem europäischen Land möglich.

Material und Methode: Die folgende Übersicht zeigt die wesentlichsten Einflussfaktoren und deren grosse Variabilität innerhalb von Europa, die eine adäquate Patientenbehandlung in ganz Europa erschweren. Um die Unterschiede zwischen einzelnen europäischen Ländern aufzuzeigen, wurden u.a. Fragebogen an Retinologen in Europa verschickt. 


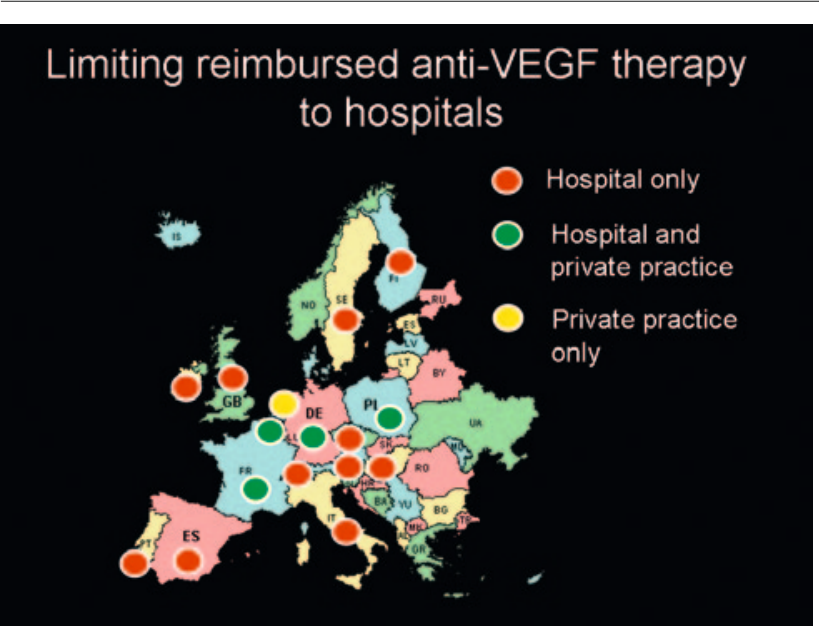

Fig. 1: Limiting reimbursement to hospitals

Zu den wesentlichsten limitierenden Faktoren gehören das in der Europäischen Union (EU) geltende Behandlungslabel für Ranibizumab und die national und teilweise regional geltenden Vorgaben für die Durchführung und Kostenerstattung der intravitrealen Therapie. Hinzu kommen teilweise regionale oder institutionelle Einschränkungen, die die Anzahl der intravitrealen Injektionen reglementieren. Die Ergebnisse zeigen, dass es innerhalb von Europa Unterschiede gibt.

Resultate: Zu den wichtigen Unterschieden gehört die Dauer des nationalen Entscheidungsprozesses zur gesetzlichen Regelung der Kostenerstattung. Dieser Prozess kann in einzelnen Ländern mehrere Jahre in Anspruch nehmen. Eine weitere Einschränkung besteht in vielen Ländern in Hinblick darauf, welche Personen/Institutionen intravitreale Injektionen durchführen darf und erstattet bekommt. Dies ist in den meisten Ländern an die Kostenerstattung durch das Gesundheitssystem gebunden. Besonders in osteuropäischen Ländern sind die Institutionen, denen intravitreale Injektionen erstattet werden, Budgets unterworfen, die adäquate evidenzbasierte Versorgung der Patienten weiter deutlich erschweren. Erhebliche Unterschiede sind zudem bei den jeweils vorhandenen räumlichen Anforderungen und Auflagen an den Raum in dem die Injektion durchgeführt wird - von lediglich designiertem Injektionsraum bis zu vollwertigem Operationssaal - feststellbar. Hier zeigt sich innerhalb Europas eine deutliche Ost-West-Verteilung. Dieser Aspekt hat u. a. einen möglichen Einfluss auf die Sicherheit, aber auch auf die anfallenden Kosten und die Effizienz der Abläufe. Zum Teil sind die erheblichen Unterschiede in der Kostenerstattung für eine intravitreale Injektion innerhalb Europas durch die Vorgaben für den Injektionsraum erklärbar. Der Preis für die Durchführung einer intravitrealen Injektion an Institutionen mit Kostenerstattung durch das Gesundheitssystem variiert innerhalb Europa von etwa 80 bis etwa $600 €$. Jedoch variiert die Kostenerstattung für die intravitreale Injektion mitunter sogar regional oder in Abhängigkeit vom Versicherungssystem.

Fast ubiquitär zeigt sich jedoch ein Mangel an finanziellen und personellen Ressourcen, um die Untersuchungs- und Behandlungsabläufe der Ära der intravitrealen Injektionen anzupassen. Dies ist von erheblichen Nachteil für die betroffenen Patienten aber auch für viele behandelnde Ärzte.

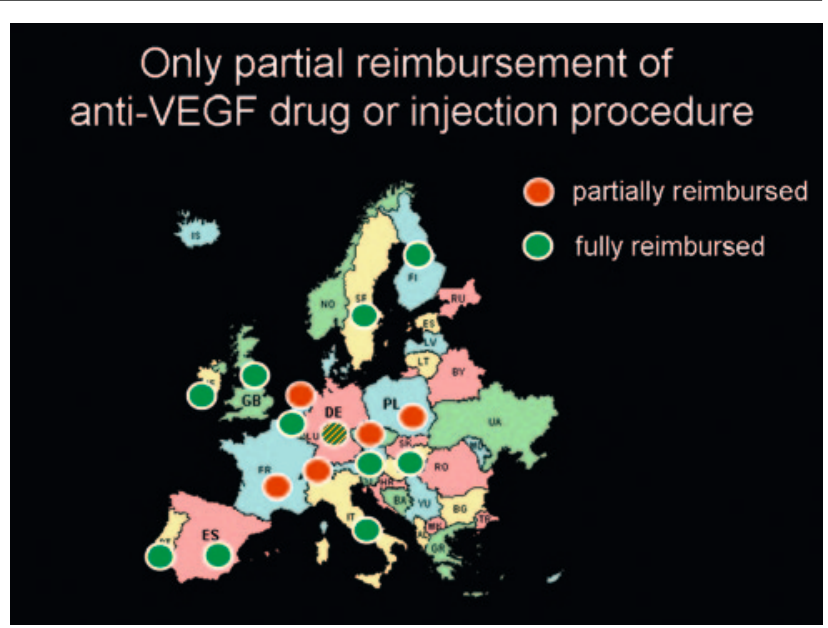

Fig. 2: Co-payment for drug and/or intravitreal injection procedure

Schlussfolgerung: Mit einer zunehmenden Anzahl betroffener und mit intravitrealen Injektionen behandelbarer Patienten wird der Druck für einen verbesserten Behandlungszugang steigen. Einheitlichere Vorgaben für die Durchführung und Kostenerstattung intravitrealer Injektionen innerhalb Europas oder zumindest auf nationaler Ebene wären wünschenswert. Leider ist ein Trend zur weiteren Regionalisierung feststellbar.

Schlüsselwörter: intravitreale Injektion, Ranibizumab, Bevacizumab, IVOM, Kostenerstattung, Anti VEGF

\section{Introduction}

Intravitreal injections of vascular endothelial growth factor (VEGF) inhibitors have become the standard of care for most exudative macular diseases. So far, only ranibizumab and pegabtanib have been approved in the European Union (EU) by the European Medicines Agency. Due to best phase III clinical study results, ranibizumab is the mostly used approved anti-VEGF drug in Europe. As of 2011 it is not only approved for the treatment of neovascular age-related macular degeneration (AMD), but also for diabetic macular edema (DME) and macular edema secondary to branch or central retinal vein occlusions (BRVO/ CRVO) based on the results of large randomized controlled clinical trials [1-5]. In any member country of the EU the approval by the European Medicines Agency is obligatory for any biotechnology drug. The approval is valid throughout the EU. Switzerland maintains an own approval process guided by the regulatory agency Swissmedic. In no European country bevacizumab is approved for intraocular injection. A preliminary approval in Italy has been withdrawn.

Limitations on the use of ranibizumab that are valid throughout the EU can be found on the official approval label [6].This label provides limitation to its use with regard to a "loading dose" at the initiation of treatment, retreatment criteria as well as minimal treatment intervals. Details on the official ranibizumab label are listed in table 1.

Of interest is that for only one of the approved indications (DME) the label is about consistent with treatment protocols of the large prospective clinical trials leading to the approval of the drug. Even for DME further large prospective clinical studies have shown in the meantime that monthly ranibi- 


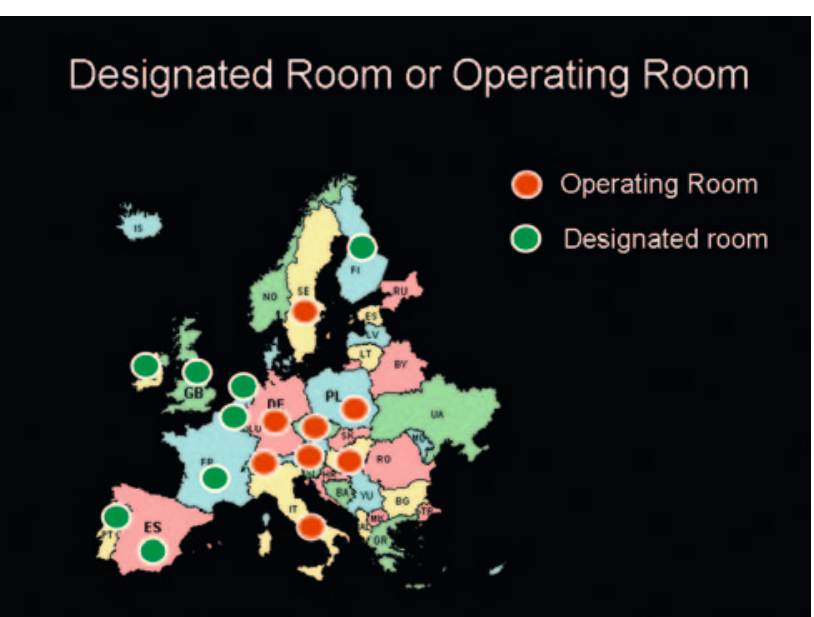

Fig. 3: Requirements for injection room

\section{TABLE 1}

\section{Label or ranibizumab (Lucentis ${ }^{\circledR}$ ) by the} European Medicines Agency ${ }^{6}$

\section{Treatment of wet AMD}

In wet $A M D$, the recommended dose for ranibizumab (Lucentis ${ }^{\circledR}$ ) is $0.5 \mathrm{mg}$ given monthly as a single intravitreal injection. This corresponds to an injection volume of $0.05 \mathrm{ml}$. Treatment is given monthly and continued until maximum visual acuity is achieved, i.e. the patient's visual acuity is stable for three consecutive monthly assessments performed while on ranibizumab treatment.

Thereafter, patients should be monitored monthly for visual acuity and activity of the disease.

Treatment is resumed when monitoring indicates loss of visual acuity due to wet AMD. Monthly injections should then be administered until stable visual acuity is reached again for three consecutive monthly assessments (implying a minimum of two injections). The interval between two doses should not be shorter than 1 month.

\section{Treatment of visual impairment due to either DME or macular oedema secondary to RVO}

The recommended dose for Lucentis is $0.5 \mathrm{mg}$ given as a single intravitreal injection. This corresponds to an injection volume of $0.05 \mathrm{ml}$.

Treatment is given monthly and continued until maximum visual acuity is achieved i.e. the patient's visual acuity is stable for three consecutive monthly assessments performed while on ranibizumab treatment. If there is no improvement in visual acuity over the course of the first three injections, continued treatment is not recommended.

Thereafter patients should be monitored monthly for visual acuity.

Treatment is resumed when monitoring indicates loss of visual acuity due to DME or to macular oedema secondary to RVO. Monthly injections should then be administered until stable visual acuity is reached again for three consecutive monthly assessments (implying a minimum of two injections). The interval between two doses should not be shorter than 1 month. zumab appears superior to the treatment indicated by the label/Restore study (ARVO 2011 - 6647 - D Brown - Ranibizumab for Diabetic Macular Edema (DME): 24-Month Efficacy and Safety Results of RISE - a Phase 3 Randomized Controlled Trial) [3,6].So, if best evidence treatment protocols are used by ophthalmologists, their treatment is most of the time not according to the official treatment guideline of the ranibizumab label in the EU. One major criticism on the treatment guideline of the label is that loss of vision is required for patients to be retreated. Currently available technologies (e.g. optical coherence tomography (OCT)) are a superior indicator for retreatment than loss of visual acuity. The PrONTO study outlined first that under anti-VEGF treatment in neovascular AMD patients visual function follows anatomic changes[7, 8]. The criticism on the label has found its way into retreatment recommendations by national ophthalmologic societies that clearly differ from the official label and recommended retreatment whenever any disease activity is detected [9]. The only country in Europe, in which the current label allows monthly treatment for neovascular AMD - as in the Phase III studies is Switzerland.

However - beyond the EU drug label for ranibizumab there are further limitations to the use of anti-VEGF drugs at the national level throughout Europe. To obtain a broad overview on the national limitations using anti-VEGF drugs a survey was sent to 50 retina specialists from 20 European countries. Key questions of the survey focused on reimbursement by the health care system, professional requirements to perform the intravitreal injection, specifications for the injection room and on the level of reimbursement for the intravitreal injection at institutions that are reimbursed by the national health care system.

The key information out of the responses of 23 retina specialists of 16 European countries was that there is limitation to anti-VEGF treatment access in any country. In addition, there is a large variability on how access to treatment is limited among the different countries. Within some countries (e.g. Italy, Spain, Portugal) there are even significant regional variations.

Only in selected countries additional qualifications of the treating ophthalmologist to perform the intravitreal injection are required. Among the exemptions is Germany, where similar to an additional qualification to perform photodynamic therapy, an intravitreal injection training course as well as training in reading fluorescein angiographies are strongly recommended by the large ophthalmologic societies [10]. Ophthalmologists without this expertise have difficulties obtaining reimbursement in the German health care system.

The first limitation for patients to get access to anti-VEGF treatments after approval of ranibizumab by the European Medicines Agency was in many European countries a significant delay on national reimbursement decisions. The reimbursement decision is - different to the drug approval process - a national decision and includes in some countries long evaluation processes and price negotiations with the pharmaceutical industry. These price negotiations at the national level are the reason for some price variability between different European countries. In general, delays due to lengthy price negotiations are more common in southern European countries. Reasons are lower attractiveness of southern Euro- 
pean markets for the pharmaceutical industry and commonly stronger market regulations[11, 12]. The United Kingdom (UK) involves many stakeholders in the reimbursement decision process guided by the National Institute of Clinical Excellence (NICE). Cost effectiveness is a key aspect in the NICE decision process, which led during the price negotiations for ranibizumab in neovascular AMD to an agreement, in which the pharmaceutical industry covers the drug cost beyond the 14th intravitreal injection [13]. A disadvantage of the process is the significant time delay until a final decision is taken [14]. The NICE guidance on ranibizumab for neovascular AMD to the National Health Service (NHS) in the UK took 1.5 years.

In many European countries the national health authorities involved in the reimbursement process have added additional - not necessarily evidence based - limitations to the use of ranibizumab.

The most relevant regulation at the national level in many European countries is however the limitation of reimbursement of anti-VEGF therapy to specific institutions only. The most common differentiation is between private ophthalmology practices and larger, mostly public hospitals. The survey revealed that in most European countries the reimbursement is limited to larger, mostly public clinics by the national or private health care systems (Fig. 1). This is clearly a disadvantage for especially the elderly AMD population living in more rural regions. In some countries - e.g. Germany - bound to the status of an institution but rather to the qualification of the treating ophthalmologist and the availability of an operating room for intravitreal injections. Only in the Neatherlands reimbursement of intravitreal injections is soley provided for private practices.

The key problem in many European countries for many patients with exudative macular disease to gain adequate access to evidence based best treatment is that institutions, where intravitreal anti-VEGF therapy is covered by the health care system, are submitted to further restrictions. In many southern and eastern European countries drug cost and/or injection procedure cost fall under a clinic budget that permits only limited use of in particular ranibizumab. The subsequent consequences to reduce cost are the splitting of ranibizumab or the off-label use of bevacizumab. In some countries (e.g. Hungary) institutions providing intravitreal injections are submitted to a regulated and limited number of surgical procedures including intravitreal injections. A further phenomenon are even counterproductive incentives. Some Italian Ophthalmology department budgets are influenced by the waiting time for new glasses and cataract surgery rather than the waiting time to treatment for a patient with neovascular AMD. This situation of extensive patient waiting lists for reimbursed antiVEGF treatment leads to patients being treated with significant delay (having had further vision loss in the meantime) or being forced into private practice without being reimbursed by the health care system.

Another aspect is the reimbursement of the intravitreal injection as surgical procedure. In many countries (e.g. Austria, Finnland, Spain, Portugal...) reimbursement of the injection procedure falls within an overall clinic budget. So, there is no incentive in increasing the number of injections and reducing the waiting time for affected patients. This situation is not only a burden for the patients but also for the treating ophthalmol-

\begin{tabular}{|c|c|}
\hline \multicolumn{2}{|c|}{$\begin{array}{l}\text { TABLE } 2 \\
\text { Compensation for intravitreal injection } \\
\text { procedure (without drug) - exchange } \\
\text { rate } 12 / 11 \text { (where applicable) }\end{array}$} \\
\hline Country & averaged cost ( $€$ ) \\
\hline Netherlands & 600 \\
\hline Switzerland & 510 \\
\hline Germany & 300 \\
\hline Sweden & 220 \\
\hline Poland & 200 \\
\hline France & 145 \\
\hline Czech Rep. & 140 \\
\hline Italy & 115 \\
\hline Hungary & 100 \\
\hline Belgium & 80 \\
\hline $\begin{array}{l}\text { Others (Austria, Finnland, } \\
\text { Spain, Portugal) }\end{array}$ & Budget \\
\hline
\end{tabular}

ogists, who have to work in suboptimal settings and have to compensate for an increasing workload. Especially in countries with a privately organized health care system co-payments for injection procedures are not uncommon (Fig. 2).

In Germany currently no specific billing code exists for the intravitreal injection procedure. The co-payment varies therefore depending on the treating physician, the private health care coverage plan, specific contracts between health care providers and physicians networks and in some cases even on the anti-VEGF drug used. In addition, follow-up visits are not always reimbursed. Due to the high number of injections and follow-up visits required, most patients are confronted with additional costs - despite official coverage/reimbursement -, which can be a major burden for patients and subsequently leads to reduced compliance and worse functional outcomes.

The compensation for the intravitreal injection as surgical procedure varies significantly within Europe. Table 2 outlines the results of the conducted survey. It provides only a limited overview since even at the national level there is a large variability due to various factors and since the survey is based on relatively few responses $(n=23)$.

Some variation can be explained by national requirements for the injection rooms. Commonly the national health authorities outline the requirements for an injection room and these are further communicated by guidelines of the national ophthalmologic societies. The requirements range from a designated room - without any further specifications - up to a fully equipped operating room with laminar airflow. Figure 3 outlines in which European countries - with minor national variations - a designated room or a fully equipped operating room is required.

Some east-west distribution throughout Europe appears evident. The national requirements for injection room have significant implications.

The first one is safety. Publications on the rate of endophthalmitis (excluding series due to improper drug preparation by compounding pharmarcies) in large injection clinics in the United States (US) - where just designated rooms are used for the injection procedure - are at the range of 1 endopthalmitis 
every 1200-5000 intravitreal injections [15, 16, 17]. A recent retrospective study analyzing endophthalmitis cases following surgical procedures and intravitreal injections in a designated room showed a higher risk for endophthalmitis with worse outcomes for endophthalmitis secondary to intravitreal injections outside an operating room [16]. In addition a large multicenter clinical trials conducted in the US and Europe indicated an overall lower risk at European centers (ARVO 2011 - 6647 - D Brown - Ranibizumab for Diabetic Macular Edema (DME): 24-Month Efficacy and Safety Results of RISE - a Phase 3 Randomized Controlled Trial). Our own experience at a swiss eye clinic - submitted to the highest standards (OR with laminar airflow) - had only a single culture negative endophthalmitis in more than 20000 injections since 2006. Obviously the current data does not prove that higher hygienic standards for an injection room are necessarily associated with a lower risk for endophthalmitis, but many of the multiple factors (mask over mouth and nose, sterile gloves...) potentially associated with a lower risk for endophthalmitis are part of the requirements of running an operating room for intraocular surgery.

The second one is cost and patient flow. The expenses on building and running an operating room with a high hygienic standard are extensive. Just the operating room and energy cost plus the amortization sum up to $12.5 €$ per minute according to Albrecht and Toepfer [18]. In addition the operating room has to have sufficiently qualified staff. In most clinics operating rooms built prior to the "intravitreal injection era" are used for intravitreal injections. This leads on the one hand to competitive displacement of other surgical procedures, on the other hand these operating rooms are often not ideally located for highly frequented injection clinics. This is a significant draw back for patient flow and a limiting factor in any effort in reducing the patients time in clinic.

As shown there are numerous obstacles in providing best evidence care to patients with neovascular AMD, with DME and edema secondary to RVO. A key obstacle in all countries of the EU is the current label for ranibizumab. Additional variable limitations occur at the national level. Even though in all European countries treatment with ranibizumab is approved and mostly reimbursed, significant obstacles prevent many patients from getting treatment on time, in an adequate setting and according to the best evidence treatment regimen. In the context of the ongoing debate on the risk for endophthalmitis using different anti-VEGF drugs, one has to reconsider under which conditions the intravitreal injection is performed. There is increasing evidence that the risk for endophthalmitis is lowest in a fully equipped operating room. This however goes together with significantly higher cost, worse patient flow and longer patient waiting time.

There is clearly need for improvement throughout Europe to provide affected patients with better and closer to best evidence care. It is likely that the rapidly growing patient population requiring intravitreal injections will increase pressure on all stakeholders.

\section{Conflict of Interest}

The authors declare that there is no conflict of interest.

\section{References}

1. Brown DM, Michels M, Kaiser PK,et al. ANCHOR Study Group. Rani bizumab versus verteporfin photodynamic therapy for neovascular age-related macular degeneration: Two-year results of the ANCHOR study. Ophthalmology. 2009 Jan;116(1):57-65.e5.

2. Rosenfeld PJ, Brown DM, Heier JS, et al. MARINA Study Group. Ranibizumab for neovascular age-related macular degeneration. N Engl J Med. 2006 Oct 5;355(14):1419-31.

3. Mitchell P, Bandello F, Schmidt-Erfurth U, et al. RESTORE study group. The RESTORE study: ranibizumab monotherapy or combined with laser versus laser monotherapy for diabetic macular edema. Ophthalmology. 2011 Apr;118(4):615-25.

4. Brown DM, Campochiaro PA, Singh RP, et al. CRUISE Investigators Ranibizumab for macular edema following central retinal vein occlusion: six-month primary end point results of a phase III study. Ophthalmology. 2010 Jun;117(6):1124-33.e1.

5. Campochiaro PA, Heier JS, Feiner L, et al. BRAVO Investigators. Ranibizumab for macular edema following branch retinal vein occlusion: six-month primary end point results of a phase III study. Ophthalmology. 2010 Jun;117(6):1102-1112.e1.

6. European Medicines Agency. Ranibizumab. Annex I. Summary of product characteristics. Available from: www.ema.europa.eu/ docs/en_GB/document_library/EPAR _ _Product_Information/human/000715/WC500043546.pdf

7. Lalwani GA, Rosenfeld PJ, Fung AE, et al. A variable-dosing regimen with intravitreal ranibizumab for neovascular age-related macular degeneration: year 2 of the PrONTO Study. Am J Ophthalmol. 2009 Jul;148(1):43-58.e1

8. Fung AE, Lalwani GA, Rosenfeld PJ, et al. An optical coherence tomography-guided, variable dosing regimen with intravitreal ranibizumab (Lucentis) for neovascular age-related macular degeneration. Am J Ophthalmol. 2007 Apr;143(4):566-83.

9. Deutsche Ophthalmologische Gesellschaft. Neue Aspekte in der Therapie der neovaskulären altersabhängigen Makuladegeneration: Kriterien der Wiederbehandlung bei der Anti-VEGF Therapie. Available from: www.dog.org/wp-content/uploads/2009/09/Stellungnahme-AMD-Ergänzung-010411.pdf

10. Empfehlung der Deutschen Ophthalmologischen Gesellschaft, der Retinologischen Gesellschaft und des Berufsverbandes der Augenärzte Deutschlands für die Durchführung von intravitrealen Injektionen (IVI). Available from: www.dog.org/wp-content/uploads/2009/09/DOG_Empfehlung_Intravitreale_Injektionen.pdf

11. Heuer A, Mejer M, Neuhaus J. The National Regulation of Pharmaceutical Markets and the Timing of New Drug Launches in Europe. Available from: www.econstor.eu/bitstream/10419/27014/1/531160157. PDF

12. Danzon, P.M., Wang, Y.R and Wang, L. The impact of price regulation on the launch delay of new drugs - evidence from twenty-five major markets in the 1990s. Health Economics 2005, 14, 262-92.

13. National Insitute for Health and Clinical Excellence. Macular degeneration (age-related) - ranibizumab and pegaptanib (TA155) Available at: http://guidance.nice.org.uk/TA155

14. Heimann H, Yang Y, Wachtlin J, Pauleikhoff D. Differences in the treatment of exudative age-related macular degeneration in Germany and Great Britain. Ophthalmologe. 2011 Jun;108(6):575-84.

15. Moshfeghi AA, Rosenfeld PJ, Flynn HW Jr, et al. Endophthalmitis after intravitreal anti-vascular endothelial growth factor antagonists a six-year experience at a university referral center. Retina. 2011 Apr;31(4):662-8.

16. Chen E, Lin MY, Cox J, Brown DM. Retina. Endophthalmitis after intravitreal injection: the importance of viridans streptococci. 2011 Sep;31(8):1525-33.

17. Shah CP, Garg SJ, Vander JF, et al. Post-Injection Endophthalmitis (PIE) Study Team. Outcomes and risk factors associated with endophthalmitis after intravitreal injection of anti-vascular endothelial growth factor agents. Ophthalmology. 2011 Oct;118(10):2028-34.

18. Albrecht M, Töpfer A. Erfolgreiches Changemanagement im Krankenhaus. Springer 2006 